\title{
Corrosion in surgical instruments
}

\author{
Fernando B. Mainier, Marcela M. C. Lopes, Sérgio S. M. Tavares, \\ Juan M. Pardal, \\ ${ }^{I}$ Escola de Engenharia, Universidade Federal Fluminense, Niterói, RJ, Brazil
}

\begin{abstract}
The surgical instruments that are on the market for use in medical and dental treatments, most of which are designed for specific actions in specific types of surgery, are usually manufactured from stainless steels, including AISI-420 and AISI-304, as well as titanium alloys. They are manufactured by many different companies, which means that the materials used to make them have a variety of sources, types of alloys, material quality, mechanical fabrication processes and costs. Surgical instruments are subject to contamination, or bacterial adherence to the instruments, from various sources, which can have an enormous impact on human health. Hospitals and clinics are well-suited environments for this to happen, since they concentrate both particularly susceptible hosts and highly resistant micro-organisms. Therefore, cleaning and sterilization of all surgical instruments after each use is essential. Typically, steam autoclaves and solutions of chlorine-based oxidants or similar chemicals are used. These methods of cleaning can cause premature deterioration of the instruments, reducing their lifespan. Unannounced inspections of hospitals often detect instruments containing small fractures, microscopic cracks, pitting, and crevices that should invalidate their use in surgery. The objectives of this study are to identify the types of corrosion that occur in the process of sterilization and to critically assess the matter in relation to the costs of the instruments available in the Brazilian market. Finally, this study aims to clarify and publicize the problem of the quality of surgical instruments that can be used in hospitals, possibly compromising the health of the population.
\end{abstract}

Keywords: - Corrosion, surgical instrument, stainless steel, quality

\section{INTRODUCTION}

Currently, most surgical instruments available in the Brazilian market are manufactured in Brazil or imported from one of several sources. Most are manufactured of stainless steels, which are more resistant to corrosion than most metallic alloys are, but, depending on the specific use for which an instrument is intended, it may also manufactured with titanium alloys and even ceramic and polymeric materials.

The most commonly used stainless steels for the manufacture of surgical instruments are AISI-304 and AISI-420, which have austenitic and martensitic structures, respectively. AISI-304 stainless steel is resistant to attack by chemical substances while AISI-420 has good mechanical strength combined with good corrosion resistance.

These instruments are tools designed for specific actions in specific types of surgery, and can have long lifespans. They can also become contaminated, however, due to the adherence of bacteria to the material, especially if there are corroded or worn areas where the adherence of deposits is facilitated by inadequate or imperfect cleaning of surgical instruments. Such contamination can have a tremendous impact on patient health. In addition, one must consider that hospitals and clinics are enabling environments for contamination and consequent host infection [1].

Critical reflection suggests that, given the large number of manufacturers and the wide variation in prices, the available surgical instruments have diverse sources, types of metallic alloys, types of packaging, technical specifications and quality of material. Such differences can have very serious consequences given the technical ignorance of many buyers and/or users.

In addition, Yasuhara et al. [2] and the World Health Organization [3, 4, 5] have proposed several guidelines to make surgical operations safer for patients, especially with regard to hospital contamination, foreign bodies, failures of equipment and/or surgical instruments, clinical analyses, etc.

In the opinions of Khan et al. [6] and Gilmour [7], there should be a systematic and constant consideration of the risk of post-operative infection, with attention to the types of surgical instruments used and the methods of their sterilization. If such a system were implemented, surgical accidents would be reduced to operational only.

According to Spry [8], a well-manufactured surgical instrument has a lifespan of about 10 years. Each instrument is designed to work according to a specific function and consequently to withstand only the standards of cleaning and sterilization that are appropriate to that function. Improper use of surgical scissors, for example, to open a bottle or to cut or drill through plastic materials or fabrics can result in defects that accumulate over time. Improper cleaning and sterilization can make such defects grow. 
Based on the observed rates of infection, some disease control and prevention groups classify medical instruments as sources of infections into three categories: critical, semi-critical and noncritical. The appropriate sterilization conditions for each type of instrument should depend on whether the instrument is invasive, that is, whether it penetrates mucous membranes and comes into contact with sterile areas of the human body, or is restricted to superficial and non-invasive actions [8].

The problem of ensuring the quality of surgical instruments is always a challenge. According to surveys conducted by Reece et al. [9] in the United Kingdom, an estimated 15\% of new surgical instruments are defective, and the incidence of defects increases as a function of how long an instrument has been used.

Considering those results, an evaluation of the qualities of the materials used in the diverse medical and dental instruments available is essential. The repeated use of systematic sterilization methods can reduce the lifespans of surgical instrument materials, which can have an immense effect on patient health.

\section{METHODOLOGY}

Four surgical instruments, two Farabeuf Retractors and two skin scissors, were selected for this study and are shown below in Figures 1 - 4. The Farabeuf Retractors are surgical mechanical elements intended to facilitate exposure of the operative field. They are used to ward off the edges of lesions, skin, subcutaneous tissue and superficial muscles. Skin scissors are used to cut and remove sections of skin.

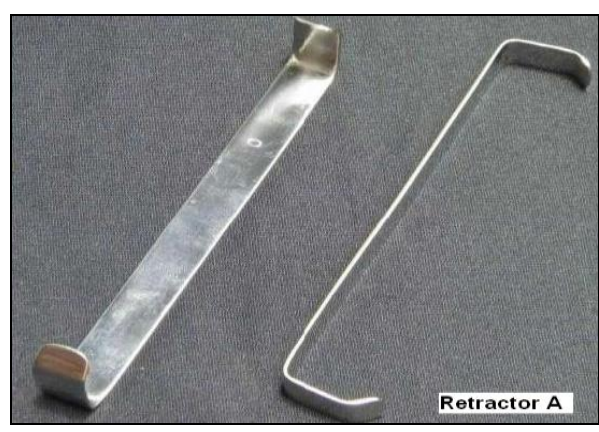

Figure 1 - Retractor A.

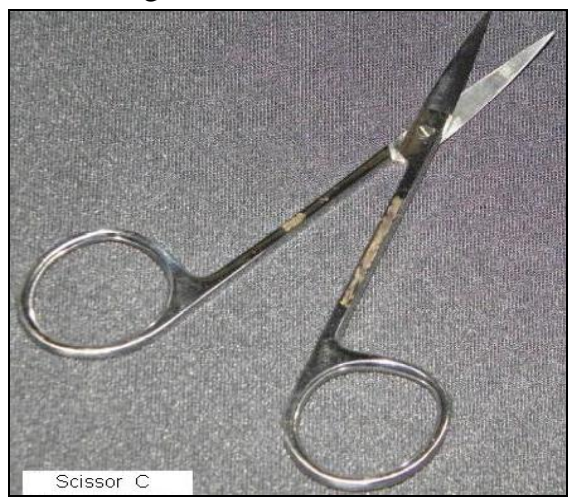

Figure 3 - Scissor C.

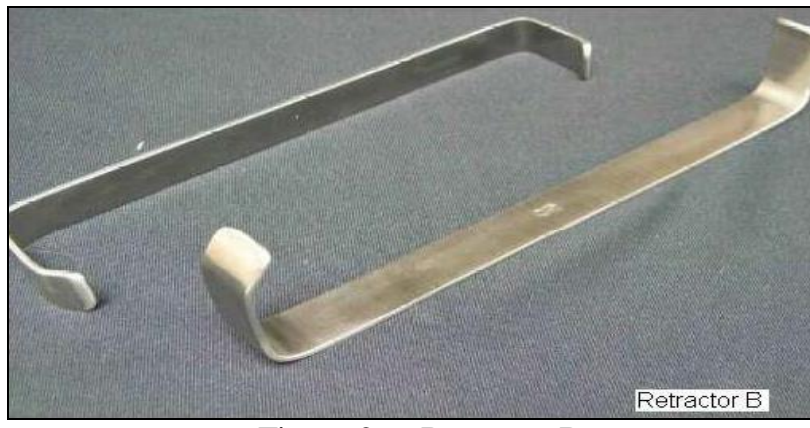

Figure 2 - Retractor B

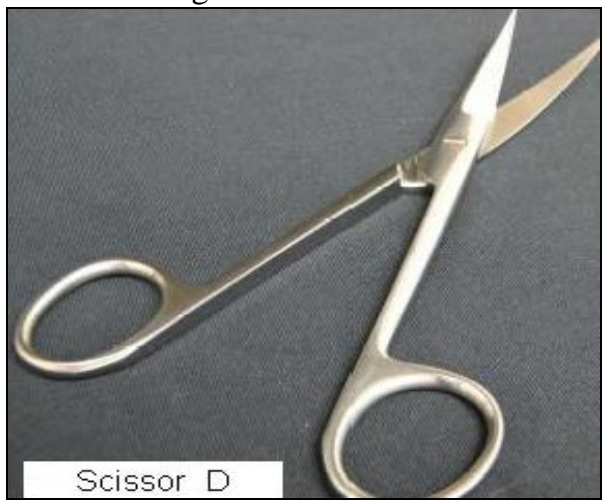

Figure $4-$ Scissor D.

Initially, these instruments were tested through metallographic analysis, chemical analysis and superficial evaluation by scanning electron microscope (SEM) in order to determine the mechanical features of their materials and workmanship. In our metallographic analysis, the samples were embedded into a mould filled with quick-curing synthetic resin and subjected to wet sanding followed by sanding with metallographic sandpapers of 100, 220, 320, 400, 500, 600 and 1200 degrees. The samples had been washed with water and polished with alumina $\left(\mathrm{Al}_{2} \mathrm{O}_{3}\right)$ of grade $1 \mu \mathrm{m}$.

To reveal the microstructures of Retractor A and skin scissors $\mathrm{C}$ and D, we applied a metallographic solution consisting of picric acid $(0.5 \mathrm{~g})$, ethanol $(40 \mathrm{~mL})$ and hydrochloric acid $(5 \mathrm{~mL})$. Retractor B was treated with a metallographic solution consisting of $10 \%$ oxalic acid solution. The instruments were subjected to electrochemical polishing consisting of immersion in the solutions referenced and the application of 8 volts for 90 seconds.

A corrosion test was administered using a potentiostat-galvanostat micro-AUTOLAB with electrochemical interface, connected to three electrodes, in an electrolytic cell using a platinum foil as the auxiliary electrode and with a saturated calomel electrode (SCE) as a reference electrode. The working electrode was applied to samples in a mould filled with synthetic resin. Polarization curves were initiated after 50 min of 
stabilization of the open circuit potential. In each sample, corrosion tests were performed using the anodic potentiodynamic polarization cyclic technique in de-aerated enzymatic detergent solution $(5 \mathrm{~mL}$ of detergent, $200 \mathrm{~mL}$ water) at room temperature $\left(25^{\circ} \mathrm{C}\right)$. Enzymatic detergent solution contains three enzymes (protease, lipase and amylase) and is recommended for the cleaning of surgical instruments, as it helps in the removal of blood, proteins, lipids and carbohydrates [10].

The anodic potentiodynamic polarization cyclic corrosion test allows the measurement of changes in current density as a function of potential. It starts by calculating the corrosion potential and progresses through other variables before returning to corrosion potential. Thus several parameters can be calculated from the results of this one test, including protective potential and pitting potential as well as corrosion potential. The protective potential can be defined as the potential below which pits that have already been formed are passivated. It is the point of intersection at which the reversal potential scan occurs. At the pitting potential, the current density increases sharply, but there is almost no change in the potential. There is also a susceptibility to pitting which is related to the area under the curve loop of polarization: the bigger the loop area under the curve, the more susceptible the material is to the formation of pitting [11].

\section{RESULTS AND DISCUSSIONS}

Metallographic laboratory analysis and scanning electron microscopy (SEM) associated with the Energy Dispersive X-ray Fluorescence (EDX) performed on retractor A revealed the characteristics of a different steel than that which the manufacturer claims that these surgical instruments are made of household appliances, coins and cutlery.

The data sheet accompanying the retractor claims that it is made of AISI-304, an austenitic stainless steel containing between 18\% and 20\% chromium, 2\% manganese, and between $8 \%$ and $10.50 \%$ nickel [12]. Analysis of the stainless steel in question showed that it is a ferritic stainless steel containing $10.50 \%$ chromium and $0.4 \%$ manganese. Ferritic steels are generally used in the manufacture of household appliances, coins and cutlery. Figure 5, below, presents the microstructure of retractor A.

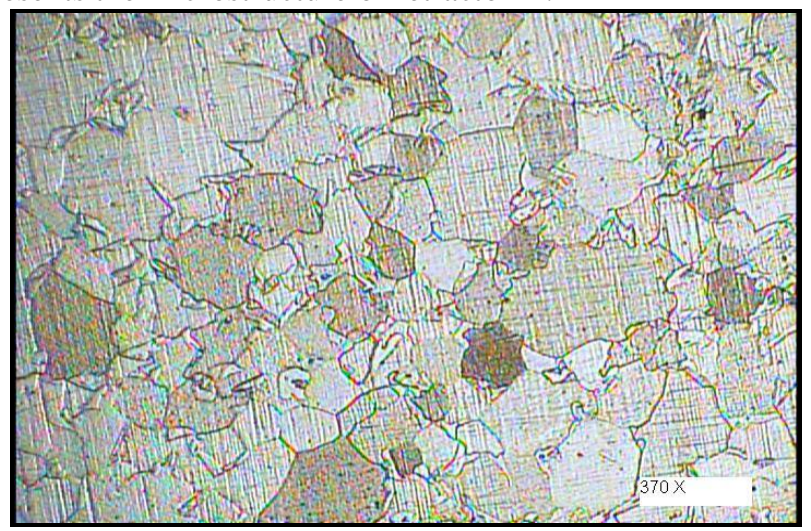

Figure 5 - Microstructure of Retractor A (370 x magnification).

Polarization assays performed on Retractor A with enzymatic detergent solution revealed evidence of pitting, as shown in Figure 6, below.

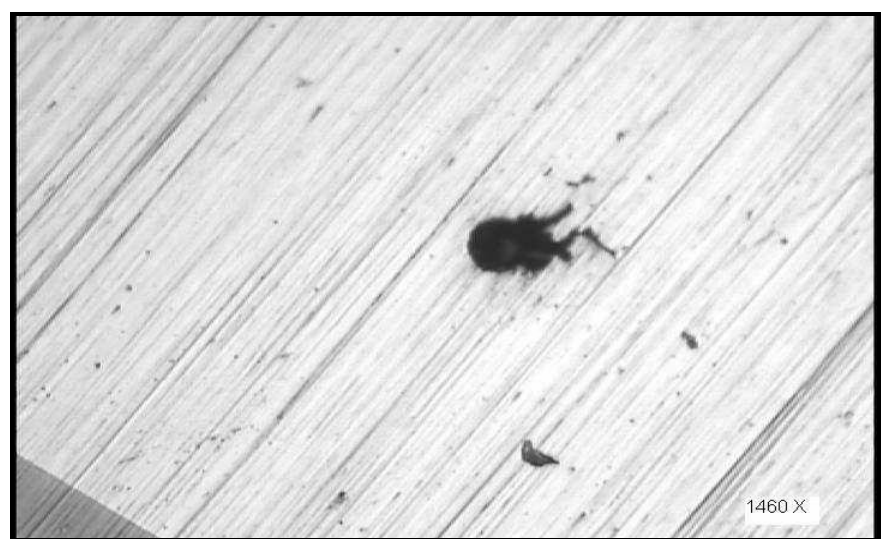

Figure 6 - Pitting visible on the surface of retractor A after polarization assay using enzymatic detergent solution (730 x magnification). 
Figure 7, below, shows the polarization curve of Retractor A, obtained in the presence of enzymatic detergent solution.

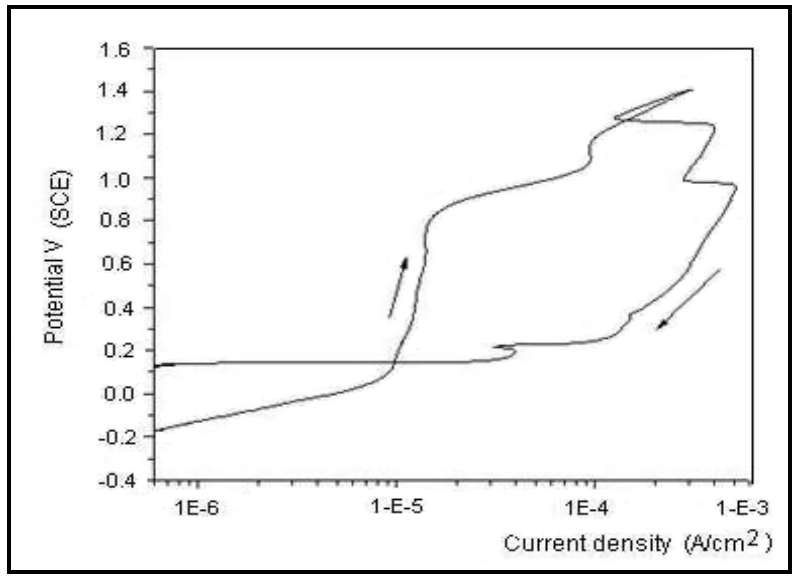

Figure 7 - Cyclic polarization curve for retractor A in enzymatic detergent solution.

Metallographic analysis of Retractor B revealed that it is austenitic steel with a sensitized structure (Figure 8). The black points are the sensitized areas. Chromium-rich grain boundary precipitates lead to a local depletion of chromium immediately adjacent to these precipitates, leaving these areas vulnerable to corrosive attack from certain electrolytes. Basically, these elements form carbides in preference to $\mathrm{Cr}_{(}\left(\mathrm{Cr}_{23} \mathrm{C}_{6}\right)$ in the austenitic alloys. However, in some corrosive media such as acetic acid at room temperature and drinking water, alkaline solutions do not cause intergranular corrosion [13, 14].

The data sheet accompanying retractor B claims that it is made of AISI 304 stainless steel, yet our analysis of the retractor indicated a chemical composition of $12.76 \%$ chromium, $0.67 \%$ manganese and $0.70 \%$ silicon. These two claims are totally incompatible.

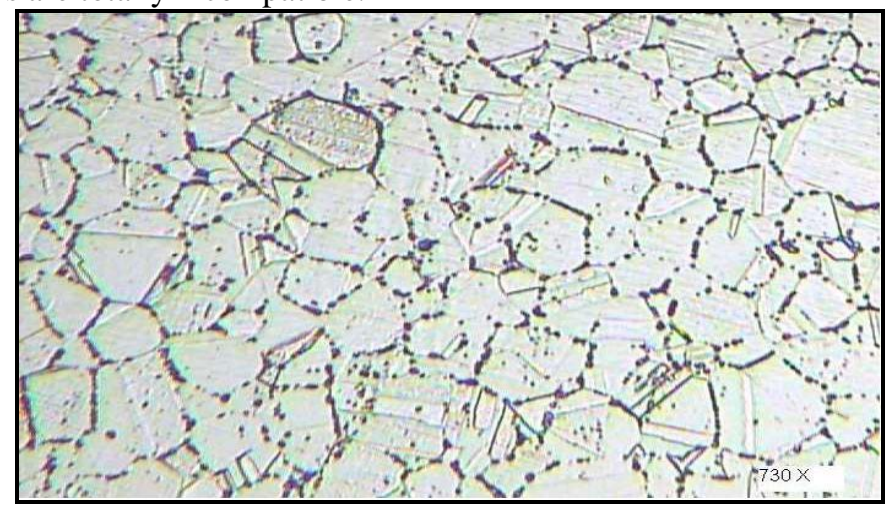

Figure 8 - Microstructure of Retractor B (730 x magnification).

Polarization assays conducted with a sample of Retractor B did not reveal any evidence of pitting, as shown in Figure 9.

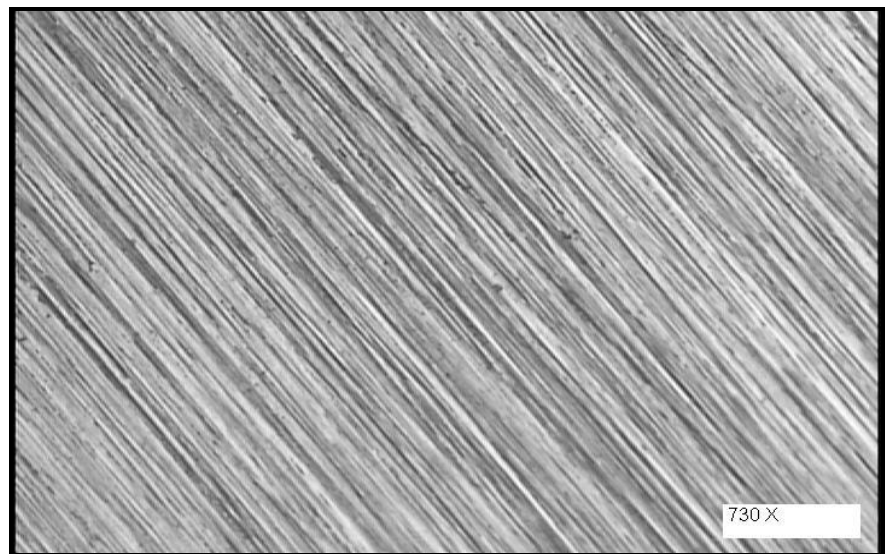

Figure 9 - Retractor B surface after polarization assay in enzymatic detergent solution (730 x magnification). 
Metallographic analysis of Scissors C revealed a microstructure of martensitic stainless steel, shown below in Figure 10. Due to its high hardness, martensitic stainless steel is the most widely used in the manufacture of surgical instruments, such as scissors and scalpels [12]. The composition obtained by ADXMEV was $11.83 \%$ chromium, $0.90 \%$ silicon and $0.20 \%$ aluminum. The data sheet accompanying the scissors claims that it is made of AISI-430, which contains between $16 \%$ and $18 \%$ chromium, $1 \%$ manganese and $0.75 \%$ nickel [15].

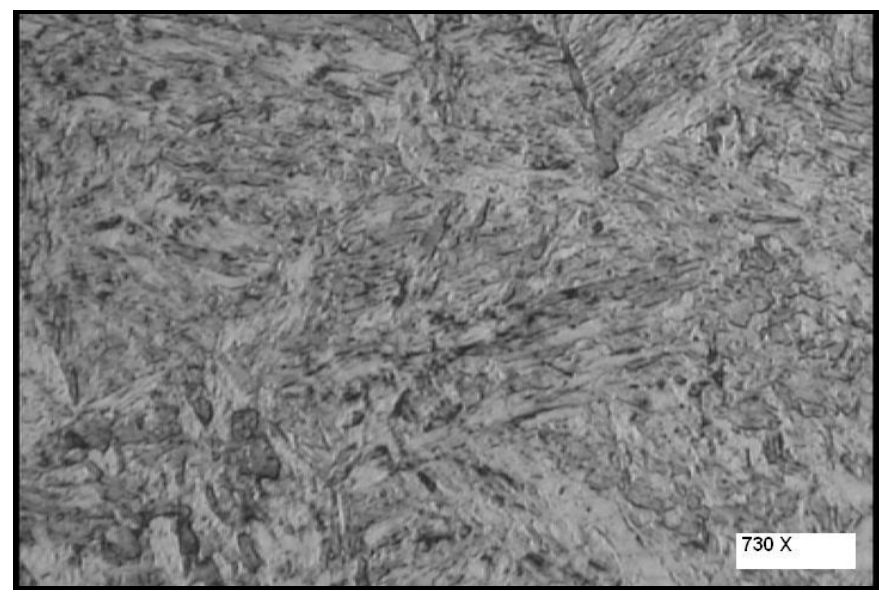

Figure 10- Scissors C microstructure (730 x magnification).

Polarization assays with Scissors C did not result in regulation, as shown in Figure 11 and in the polarization curve presented in Figure 12, below.

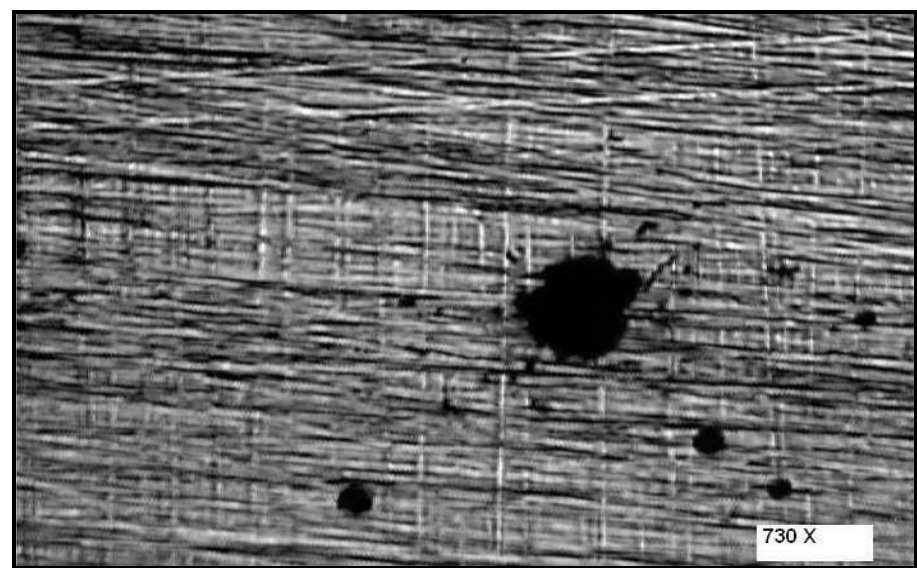

Figure 11 - Pitting visible in the surface of Scissors $\mathrm{C}$ after testing for polarization in enzymatic detergent solution (730 x magnification).

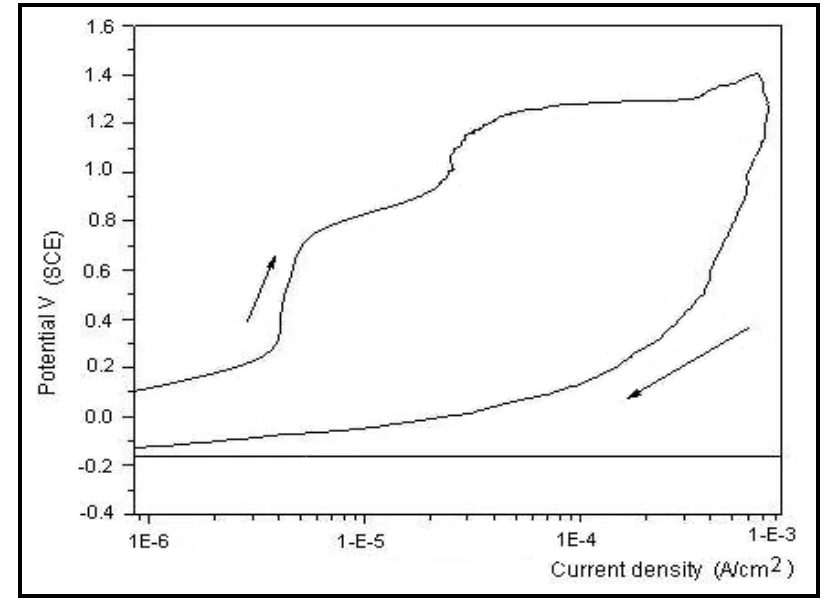

Figure 12 - Polarization curve of Scissors $\mathrm{C}$ in enzymatic detergent solution. 
Scissors D has a metallographic microstructure difficult to identify, as shown in Figure 13. The manufacturer of this scissors did not specify the type of stainless steel used in manufacturing in the technical bulletin. The results of the ADX-MEV showed a composition of $12.76 \%$ chromium, $0.70 \%$ manganese and $0.67 \%$ nickel.

Figure 14, below, shows the pitting formed in the surface after the polarization test in samples of Scissors D in enzymatic detergent solution.

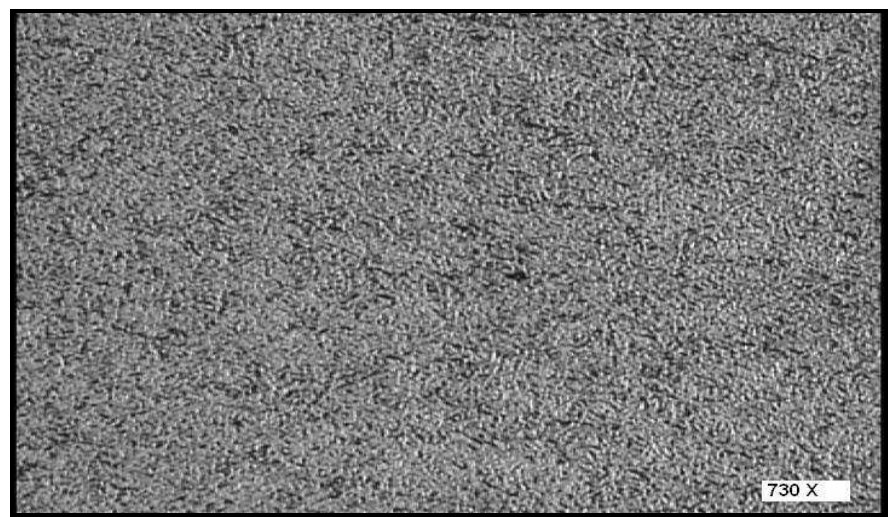

Figure 13 - Microstructure of Scissor D (730 x magnification).

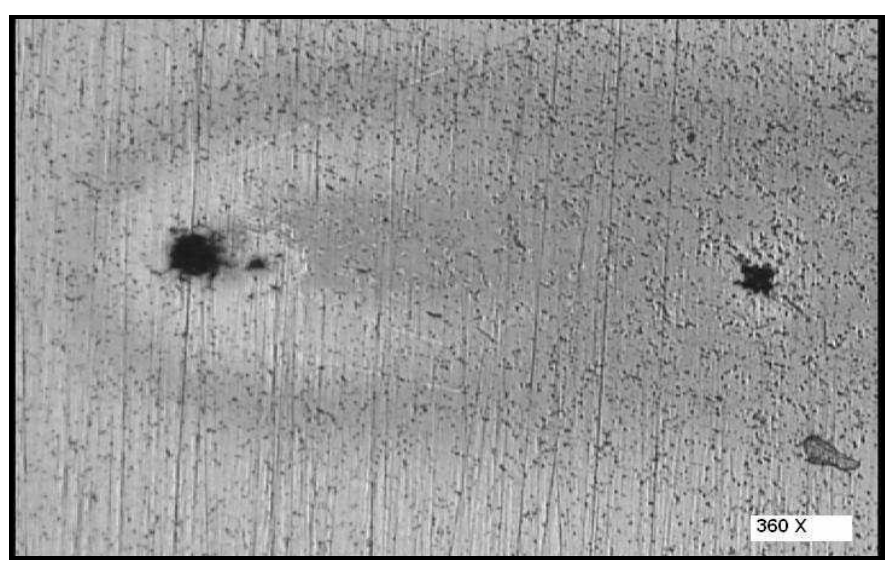

Figure 14 - Pitting visible in the surface of Scissor D after testing for polarization in enzymatic detergent solution (360 x magnification).

Figure 15, below, shows the polarization curve of Scissor D obtained in the presence of enzymatic detergent solution

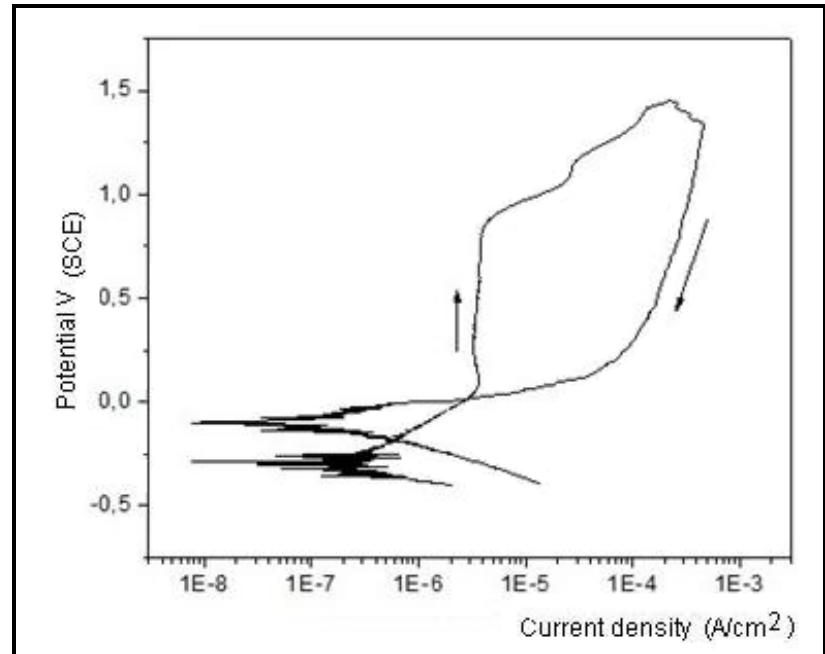

Figure 15 - Polarization curve for Scissor D in enzymatic detergent solution. 


\section{CONCLUSIONS}

On the basis of tests, we concluded that:

- All samples tested showed some kind of problem with the quality of the material used in its manufacture;

- Retractor B was composed of sensitized stainless steel, which is susceptible to intergranular corrosion, and thus has a limited lifespan;

- Analysis of Retractor A showed that it was made of a different steel than the one claimed by the manufacturing company, a steel that is not recommended for the purpose of Retractor A. Of the instruments analyzed, Retractor A was among those for sale at the lowest price;

- The company responsible for manufacturing Scissors D did not report the stainless steel used in manufacturing. The microstructure revealed was difficult to identify, and identification was only possible by means of scanning electron microscopy;

- The compositions of all steels that were found through ADX-MEV were different from those found in the literature;

- It is essential that every hospital has a strict policy of quality surgical instruments, because any possibility of contamination can lead to serious consequences both for patients and for doctors;

- The national and international markets present a wide variety of brands for purchase without technical specifications or manufacturing facilities for these instruments;

- It is crucial that purchasers of such instruments for hospital units through public edicts should choose brands and instruments with attention to quality and not only price;

- It is important to note that using instruments of insufficient quality can endanger the health of patients.

\section{REFERENCES}

[1] A. T. Moriy and J. L. P. Módena, Assepsia e Antissepsia: Técnicas de Esterilização. In: Fundamentos em Clínica Cirúrgica $1^{\mathrm{a}}$ parte, 3, Ribeirão Preto, 2008.

[2] H. Yasuhara, K. Fukatsu, T. Komatsu, T. Obayashi and Y. Uetera, Surgical Outcome Research: Prevention of medical accidents caused by defective surgical instruments, Surgery, 151, number 2, February, 2012, 153-161.

[3] D. Pittet, B. Allegranzi and J. Boyce, The World Health Organization guidelines on hand hygiene in health care and their consensus recommendations. World Health, 30(7), 2009, 611-622

[4] P. Bennett, Risk communication and public health (Oxford University Press, 2010).

[5] E. D. Belay, L. B. Schonberger, P. Brown, S. A. Priola, B. Chesebro, R. G. Will and D. M. Asher, Disinfection and Sterilization of Prion-Contaminated Medical Instruments. Infection Control and Hospital Epidemiology, 31(12), 2010, 1304-1306.

[6] S. A. Khan, A. Kumar, Y. M. K. Varshne, V. Trikha and C. Yadav, Accidentally falling instruments during orthopedic surgery: time to wake up, Surgery, 78, 2008, 794-795.

[7] D. Gilmour, Instrument integrity and sterility: the preoperative practitioner's responsibilities. Journal of Perioperative Practice, 18, 2008, 292-296.

[8] C. C. Spry, Care and Handling of Basic Surgical Instruments, AORN (Association of periOperative Registered Nurses) Journal, volume 86, 2007, 77-81.

[9] M. Reece, N. D. Troeleman, J. E. McGowan and J. P. Furuno, Reducing the incidence of retained surgical instrument fragments, AORN (Association of periOperative Registered Nurses) Journal, vol. 94, no. 3, September, 2001, 301-304.

[10] Brasil. Ministério da Saúde. Secretaria de Assistência à Saúde. Informe Técnico no 01/09. Princípios básicos para limpeza de instrumental cirúrgico em serviços de saúde, Fevereiro, 2009.

[11] N. A. Mariano et al. Avaliação da resistência à corrosão em aço inoxidável martensítico tipo Cr-Ni em meio marinho sintético simulando atividades em águas profundas. Rev. Esc. de Minas, Ouro Preto, v. 59, n. 1, p. 135-139, Janeiro/Março, 2006.

[12] N. Perez, Electrochemistry and Corrosion Science, (New York: Kluwer Academic Publishers, 2004).

[13] P. A. Schweitzer, Fundamentals of corrosion: Mechanisms, causes and preventative methods, (New York: Taylor \& Francis Group, LLC, 2001).

[14] A. L. Golin, Análise do comportamento de ferramentas de corte com diferentes revestimentos e seu efeito sobre a geração de calor no osso. Dissertação (Mestrado em Engenharia Mecânica) - Centro de Ciências Exatas e de Tecnologia da Pontifícia Universidade Católica do Paraná, Curitiba, 2005.

[15] ASME, American Society of Mechanical Engineers. Specification for heat-resisting chromium and chromium-nickel stainless steel plate, sheet, and strip for pressure vessels. SA-240, 2004, 10 p. 